\title{
FESTSCHRIFT
}

\section{Juggling law, ethics, and intuition: practical answers to awkward questions}

A Sommerville

J Med Ethics 2003;29:281-286

The eclectic problem solving methodology used by the British Medical Association (BMA) is described in this paper. It has grown from the daily need to respond to doctors' practical queries and incorporates reference to law, traditional professional codes, and established BMA policies - all of which must be regularly assessed against the benchmark of contemporary societal expectations. The two Jehovah's Witness scenarios are analysed, using this methodology and in both cases the four principles solution is found to concur with that of the BMA's approach. The author's overall conclusion is that although the BMA resorts to a lengthier list of thins to consider, the solutions that emerge are often likely to coincide with the four principles approach.

Correspondence to: Professor A Sommerville, Head of Ethics Department, BMA House, Tavistock Square, London WC1H 9JR, UK; asommerville@bima.org.uk

Accepted for publication 25 June 2003
$\mathrm{P}$ art of the fascination of medical ethics derives from the interplay of different perspectives and principles in the search for morally coherent solutions to ethical dilemmas. Practical problem solving involves verifying the facts in as accurate a manner as possible before weighing up the different values and interests to reach an acceptable balance. Although there may be various ways of doing this, modern methodologies are likely to come up with similar solutions. This is because most of us draw upon the same shared pool of established values although we may quote different justifications for respecting them. For the practical decision maker as opposed to the theoretician, legal boundaries and societal mores also increasingly limit the range of choices that can be made even before we begin to examine the ethical arguments. Indeed, in some situations, the legally viable options are so clearly and unambivalently stated that it may seem superfluous to look beyond them if the aim is to provide practical advice. The obligation to look beyond statute and legal precedents, however, springs from the need to ensure that ethical advice is morally consistent and justifiable in different contexts, regardless of whether the law has pronounced upon all the relevant scenarios. Practical ethical advice must also be consistent with society's changing expectations, especially in areas where the law is open to interpretation. The risks of relying on unscrutinised past medical practice and ambiguous legislation concerning organ retention, for example, were highlighted by the public inquiries at Bristol and Alder Hey. ${ }^{12}$ Furthermore, although account must be taken of general societal expectations, British medicine is practised in a diverse and multicultural setting where individual patients' preferences about who decides what for whom may vary. Some patients choose to waive certain of their legal and ethical rights when treatment decisions are made (which can involve complications about whether they can validly decide not to have certain crucial information without knowing how crucial it is). Among other things, this paper is about the need for practical guidance to focus strongly on the individual circumstances of each case as well as taking account of the law, ethical theories, and the requirement for medical decisions to be consistent, clinically sound, and evidence based.

The vast majority of practical ethical dilemmas in medicine involve staple examples of conflicting moral imperatives. Nevertheless, medical technology can produce new twists on classic dilemmas and so systems of problem solving should be adaptable to foreseeable future problems. They should be able to address in a consistent way exceptional as well as routine questions. Unlike the neat dimensions of textbook dilemmas, real life problems can be "rather messy concoctions of many details, some salient, others obscure, but all calling for attention". ${ }^{3}$ The reasoning applied to them must be logical and philosophically sound but also robustly practical and flexible. Human emotions are obviously complex and sometimes undisciplined but they cannot be excluded from the picture. Respecting patients' autonomy involves respecting their intentions-if knowablewhich can be a different matter from respecting the words spoken. A very common dilemma, for example, centres around the thriving, self confident, and content patient, apparently fully recovered from mental illness, who probably knows but prefers to ignore that this happy state depends on clandestine medication administered by relatives. Whether patients' self deception and collusion must automatically be challenged, and whether it benefits or harms them to do so, might conceivably have different answers in different contexts. Undoubtedly, we need pure, clear lines of ethical reasoning for the establishment of norms and standards but real life dilemmas often tend to involve ambiguities, inconsistencies, mutually incompatible desires, and ragged edges. Frequently not all the pieces of the jigsaw are available because information has been withheld or lost or misinterpreted through human error. Flexibility, interpretation, and some juggling skills may be required and they are also part of the British Medical Association (BMA) approach. 


\section{COMPONENTS OF THE BMA'S METHODOLOGY}

In some respects, the BMA's methodology has much in common with a four principles approach. It is based on the premise that moral solutions cannot be reduced to a set of one size fits all rules and algorithms. Context is important. The association does not provide "answers" to doctors' dilemmas but rather sets out the legal and moral arguments, indicating what appears most ethically justifiable in a specific context. By disentangling the morally relevant issues of the dilemma from the clutter of information surrounding them, the BMA seeks to highlight the competing interests that need to be balanced in a particular situation. Although staple questions recur, ready made answers cannot necessarily be applied, precisely because the requirements of some or all of the individuals concerned can vary from case to case. Thus, as with the four principles approach, potential solutions depend on the weight and priority given to particular values in the context of individual cases. In every dilemma, it is crucial first to clarify the facts and details. Within the BMA's methodology, it is then generally necessary for us to consider:

1. The law, including the implications of human rights legislation;

2. Established professional guidance;

3. Relevant legal and ethical definitions of "harm" and "benefit" in particular contexts;

4. Doctors' traditional values and duties;

5. The available clinical evidence base, especially for innovative practices;

6. Community values in terms of issues such as patient autonomy and its limits, the need for transparency, protection of vulnerable individuals, and the need to accommodate cultural and religious diversity;

7. The need for consistency-not just with existing advice and policies but also looking ahead to identify future ethical dilemmas.

For the most part, these components are self explanatory but it may be worth focusing on why factors such as the law, professional guidance, and traditional values feature prominently in the BMA's methodology. Interpretation of what constitutes a "benefit" or "harm" is likely to be central to any problem solving methodology but this too is an area in which the law increasingly plays a role, with the consequence that very detailed professional guidance is developing about how the terms should be defined in specific circumstances.

\section{Law}

Glancing back in time, we see that the values underpinning past medical paternalism which intended in their own fashion to minimise perceived "harm" and maximise patient confidence, made doctors the prime decision makers for far too long. After paternalist attitudes came under attack in the 1960s and 70s, parliament and the courts increasingly came to be seen as the correct arbiters of the most complex dilemmas in medicine. In Britain, questions such as whether a wife should have control of her dying husband's sperm, whether assisted suicide should be a patient's right or whether it is acceptable to keep alive a person in a persistent vegetative state have ultimately been resolved by the law. In 2001, the Lord Chief Justice of England and Wales pointed to a radical shift in public attitudes, focused on individuals' enforceable rights. ${ }^{4}$ He referred to a general "move to a rights based society" in which the courts rather than doctors would increasingly be the ultimate arbiters on questions of medical ethics. This does not mean that doctors' dilemmas have evaporated or can simply be referred to a judge but rather that any practical recommendations for action should be consistent with statute and case law precedents. Medical expertise and traditions still inform legal outcomes and it is well recog- nised that the type of issues addressed by medical law have important philosophical, ethical, sociological, religious, and political dimensions as well as legal ones. ${ }^{5}$ Some ethical approaches (and many aspects of good medical practice) have long focused on patients' moral rights and human rights' language has increasingly permeated ethical discourse. From a very practical perspective, however, arguments about moral rights may increasingly be overtaken-for example, on issues like euthanasia-by legal interpretation of the human rights now formally reflected in British law. The human rights legislation has significant implications for medicine, particularly in terms of issues such as treatment refusal. The BMA has published specific guidance on the Human Rights Act 1998 and its implications for doctors. ${ }^{6}$ The BMA's approach recognises that the relationship between ethics and law is a reciprocal one. In practical terms, "it is pointless to attempt to disengage the moral from the legal dispute-when we talk about legal rules, we are inevitably drawn into a discussion of moral rules."

\section{Professional guidance}

Professional guidance attempts to distil relevant ethical and legal thinking into some kind of consensus statement. It may also refer to traditional principles concerning doctors' duties to act with compassion, provide "benefit", respect confidentiality, and demonstrate integrity in their relationships with colleagues and patients. Such values, generally labelled "Hippocratic" find echo in the writings of all the great philosopher/physicians. Throughout history, different cultures have exhorted doctors to distinguish themselves by their adherence to such virtues. By constant repetition, such aspirations become seen as part of what it is to be a doctor and form the basis of what might be termed doctors' professional conscience. They remain relevant because doctors generally want solutions that not only make logical and legal sense but also do not contravene their intuitions about the core purpose of medicine and the role of the healer. For example, many doctors would see it as fundamentally wrong and counterintuitive for the profession to be involved in judicial executions and lawful punishments such as amputation, even though local law may require it and doctors could reduce the subject's suffering. Although conscience and intuition alone can be unreliable indicators, when combined with other considerations, they can be a useful component of professional consensus guidelines.

In practice, BMA advice must reflect the views of the regulatory body for medicine, the General Medical Council (GMC) whose guidance is binding on doctors and provides the framework for further discussion. To this, the BMA adds its interpretation of how the guidance is likely to apply in the specific contexts raised by doctors' dilemmas. Sometimes such advice may seem parochial or overly obsessed with practical detail rather than providing a thorough rehearsal of broad philosophical arguments. This is partly because doctors' practical requirements are obviously not the same as those of teachers and bioethicists. For the purposes of teaching and debate, discussion often reflects a purist approach centred on the empowerment of the stereotypical competent, rational, freestanding individual. In life, both patients and doctors can feel vulnerable and unsure about the choices offered. Decisions are seldom freestanding but can deeply affect other people, including patients' loved ones and dependents. In some dilemmas, the interpersonal relationships and complex motivations of love, guilt, pity, and desperation need to be acknowledged and addressed. In many areas, medicine is still an inexact science so that risk and uncertainty bedevil all the options. Doctors also want guidance that seems to them to be intuitively correct and consistent with what they understand to be the core purposes of medicine. Moral justifications for various actions are rehearsed but practical solutions sometimes arise quite unexpectedly from intuition or a doctor's 
hunch that an improbable solution could work, rather than solely from rational analysis.

\section{Interpretations of "harm" and "benefit"}

Notions of maximising benefit and minimising harm have always been central to traditional professional codes as well as to a four principles approach. Compassion and the promotion of human flourishing are expressed in medical ethics statements in all cultures and epochs. Traditionally, keeping people alive and functioning as well as possible has been what most doctors understood by the obligation to avoid "harm" and promote "benefit". But although the terminology easily crossed cultural and historical divides, the interpretations of the terms has not necessarily done so. Some doctors-for example, have argued that carrying out traditional practices such as female genital mutilation is consistent with the concept of providing benefit or, at least, minimising harm. ${ }^{8}$ Among the controversies brewing in medical ethics is that concerning the status of male infant circumcision which some people classify as a non-therapeutic and therefore harmful assault on a child and others see as conferring a range of benefits, including social integration and cultural acceptance. Although they can be slippery, notions of "harm" and "benefit" continue to feature strongly in the BMA's problem solving methodology and increasingly preoccupy the courts, even though there is no clear and universalisable definition. As with the four principles approach, interpretation of the terms depends, in different contexts on a number of variables, including individuals' perceptions as well as legal and professional benchmarks.

The New Dictionary of Medical Ethics defines "harm" thus: "nothing is harmful unless it is bad for the one harmed; thus harm is intrinsically an evaluative concept. Subjectivist accounts state that harm is necessarily a subjective matter, with the evaluation of the person potentially being harmed being determinative". ${ }^{9}$ Objectivist accounts take a different view. In the past, doctors based their decisions on a mixture of their own conscience and intuition, received wisdom, and codes of practice. They were fairly certain that they knew how to interpret "harm" and "benefit" but their views were unlikely to be based on patients' subjective views. In respect of Jehovah's Witnesses, most doctors now accept unhesitatingly that some patients view blood as a "harm" rather than "benefit" for them. Dilemmas still arise for doctors who define "benefit" and "harm" in terms of clinical outcome alone and for those who have a conscientious objection to allowing patients to die when they could be saved. In those cases, as with the four principles approach, there needs to be discussion of the moral and legal priority generally accorded to patient autonomy within society as whole, as well as in professional guidance and case law. If unable to accede to a competent adult patient's refusal, legal and professional guidance requires the doctor to stand aside and transfer the patient's care to another practitioner.

In other cases, patient autonomy may be differently weighted. For example, some newly delivered mothers who have previously undergone female genital mutilation and consider it to be a cultural right and benefit, ask to be resutured following their baby's birth. Similarly, the fact that competent people with body dysmorphia see amputation of healthy limbs as a benefit can raise problems with the subjective harm/benefit interpretation. The BMA still argues that where adults are informed, competent, and unpressured, they are generally the best judges of benefit and harm for themselves but if their choices clearly conflict with other moral imperatives, they are unlikely to be determinative. This is similar to the principlist argument that respect for autonomy can only be binding if it does not conflict with another principle. As with the four principles approach, the BMA's eclectic approach also brings in a range of other potential considerations to temper the focus on autonomy, including legal arguments, societal expectations, and traditional Hippocratic values. Intuitively too, doctors perceive the overall aim of medical treatment as being the promotion of healthy functioning and the minimisation of disability and impairment. (Such terms, however, may be open to interpretation in specific contexts.)

\section{APPLYING THE BMA METHOD: THE STANDARD ADULT REFUSAL CASE}

The BMA's methodology is applied here to two staple questions: the right of adults to decline essential life prolonging treatment for themselves (the standard Jehovah's witness case) and the potential for them to refuse it for their children (the standard child of a Jehovah's Witness case). ${ }^{10}$

A first step with any problem solving methodology must be to identify the key facts and consider the dilemma in context. In any situation, it is important to see patients as individuals rather than stereotypes. The legal case of " $\mathrm{T}$ " mentioned below highlights the potential risks of applying labels to individuals or relying on assumptions about their beliefs. Among those who describe themselves as Jehovah's Witnesses, as with any group, there are people with varying degrees of conviction and commitment to the tenets of that faith. Individuals should be given full information in privacy. They need to know how great the risks are for their preferred treatment and have an opportunity to indicate whether there is any compromise they would consider. In some contexts, Jehovah's Witnesses may accept treatments such as dialysis, heart bypass, or organ transplants. Most accept non-blood replacement fluids or plasma derivatives and are generally very anxious to cooperate in every way with alternative options. Although most Witnesses do not accept their own blood donated in advance, some do or, where appropriate, are willing to accept the use of blood salvage equipment that serves to recycle their blood in a continuous circuit. Not all of these measures are likely to be relevant considerations but clearly it is important for clinicians to understand the conceptual framework within which individual patients think, rather than make assumptions about their beliefs.

\section{i) Identifying relevant legal parameters}

There is both case law and potentially relevant statute. In the 1992 appeal court hearing of the case of "T", for example, the judge emphasised the legal right of every competent adult to accept or refuse treatment, even where refusal risked permanent injury or premature death. This legal right pertains "regardless of whether the reasons for the refusal were rational or irrational, unknown or even non-existent". ${ }^{11}$ Arguably, however, the " $\mathrm{T}$ " case indicated that doctors had to look beyond patients' superficial response, check the intention behind it, and ensure that they provided full information to the patient in privacy. " $\mathrm{T}$ " was a young woman, injured in a car accident when 34 weeks pregnant. She had been raised by her mother who was a Jehovah's Witness. Although not a Witness herself, she told nurses that she still adhered to some of her mother's beliefs and signed a form refusing blood. Coincidentally, these conversations only occurred after private discussions with her mother. " $\mathrm{T}$ " was not explicitly told that a transfusion might be needed to save her life. When she became unconscious and in need of blood, an emergency hearing before a judge authorised a transfusion. At a second hearing, the judge confirmed his view that " $\mathrm{T}$ " had neither given valid consent or refusal in the emergency situation that arose. She had been unable to make a considered decision because of her medical condition and because she had been subjected to the undue influence of her mother. If, in private discussion with him, none of these arguments apply to our patient with an ulcer, his view must prevail.

With the cultural shift that has occurred within society to a focus on rights, including legally enforceable rights, such 
refusal questions are likely to be addressed initially in terms of human rights. Under the Human Rights Act, relevant considerations include the right to privacy and the right to respect for one's religious beliefs. The Act incorporated into UK law the substantive rights set out in the European Convention on Human Rights. Not only are doctors required to observe the rights in reaching decisions, they must be able to demonstrate that they have done so. Issues such as respect for human dignity, communication, and consultation are pivotal to the convention rights. In making any medical decision, doctors must consider whether an individual's human rights are affected and, if so, whether it is legitimate to interfere with those rights. Any interference with a convention right must be proportionate to the intended objective. This means that even if there is a legitimate reason for interfering with a particular right, the desired outcome must be sufficient to justify the level of interference proposed. Where different rights come into conflict doctors must be able to justify choosing one over the other in a particular case. In this case, doctors need to understand that in law, this patient's right to be free of interference would prevail.

ii) Identifying relevant professional or clinical guidance In all their medical decisions, doctors must conform to the binding guidance issued by the GMC, which emphasises the need for effective communication and helpful dialogue. ${ }^{12}$ Other than in an emergency or when caring for an incapacitated patient, free and voluntary patient consent is essential. Intervening contrary to an informed and competent refusal would raise a question of professional misconduct.

In terms of other professional guidelines, we could also turn to the Guidelines for the Blood Transfusion Services in the UK. These clearly state that staff must be sensitive to patients' individual needs, values, beliefs, and cultural background. They stress the importance of:

- doctors being aware of Jehovah's Witnesses' beliefs in relation to blood products and of non-blood alternatives;

- giving each competent patient the opportunity to discuss treatment options in confidence with a well informed doctor, and

- staff taking note of any card carried by the patient and of obtaining a signed refusal. ${ }^{13}$

\section{iii) Professional conscience and established practice}

For over 20 years, standard BMA advice ${ }^{14}$ has been that when confronted by adult Jehovah's Witness patients refusing blood, doctors must discuss with patients the likelihood of increased risks involved with the prohibition on blood and either agree to continue the procedure on the patient's terms without blood or refer to another doctor who would do so. Therefore, doctors who have a conscientious objection to complying with the patient's wishes must ensure that a colleague takes over the patient's management. The BMA's ethical advice has remained consistent although differently nuanced over the years. (Current advice, for example, is far more concerned with providing support for families and trying to find common ground rather than resorting to confrontation or the courts.)

\section{iv) Clinical evidence}

In this case, the patient requests what from the clinical perspective is a suboptimal or risky procedure in preference to a proven safe procedure (although Jehovah's Witnesses often argue that health professionals may be unduly complacent about blood so that insufficient attention is given to the risks associated with blood transfusion). Doctors' decisions must be evidence based. Treating clinicians may need to check the supporting evidence for possible alternatives to blood or bring in a more experienced colleague with appropriate knowledge.
Although they are evolving, non-blood procedures are innovative and may be beyond the expertise of some clinicians. In some spheres, however, "bloodless" medical procedures are becoming commonplace, including successful organ transplants without blood. Lists of centres of excellence in bloodless surgery and of doctors experienced in working constructively with Jehovah's Witnesses are held by the Jehovah's Witness hospital liaison committees. Clinicians might contact the Hospital Information Services for Jehovah's Witnesses which provides information about alternative therapies and references to the medical research which supports these. ${ }^{15}$

\section{v) Community values and respect for diversity}

During the 20 years in which the BMA's standard advice has been to respect a refusal by Jehovah's Witnesses, there have been major cultural changes within society. In the past, the attitudes of Jehovah's Witnesses might have been seen as eccentric or aberrant, partly because the notion of patients refusing treatment or challenging doctors' views was uncommon. It is notable, for example, that the BMA's ethics handbooks of the 1980s do not envisage that patients or parents other than Jehovah's Witnesses, would ever be likely to refuse life prolonging treatment. This is no longer the case and clearly there is now far more questioning of medical advice by patients in many everyday contexts. Unlike current BMA advice, the old sections in BMA handbooks on patient consent to treatment are not mirrored by standard sections on treatment refusal. Nowadays, however, refusal by Witnesses is simply a common facet of a wider trend. It is increasingly conceivable that other patients may decline blood or request non-blood alternatives, not for reasons of conscience but, for example, from fears about contamination by CJD. In each case, the importance of understanding the patient's particular concerns cannot be overemphasised.

\section{vi) Consistency}

Consistency with past BMA advice about treatment refusal would require compliance with the patient's views. What about other potential parallel kinds of dilemmas? In terms of respecting patients' consciences, the BMA is increasingly asked whether all patients should be routinely told that the gelatine in intravenous fluids widely used in resuscitation or anaesthesia is generally of bovine origin. Clearly, this could be problematic for Hindu or vegetarian patients in the same way as blood products may be for Jehovah's Witnesses. Also, since the cows in question are not killed under Kosher or Halal codes of practice, this may be a problem for strict Jewish or Muslim patients. Such cases may be particularly difficult when the product needs to be administered in an emergency setting, such as a paramedic dealing with a traffic accident when alternative products might not be easily available. Gelatine is also used extensively in drug capsules. By not bringing these facts routinely to patients' notice and allowing them to refuse or request an alternative, modern medicine might be thought to be following the sort of self certain, paternalistic line that doctors were accused of decades ago in relation to Jehovah's Witnesses. Consistency demands that we look ahead to these and other potentially similar cases with a view to producing guidance.

\section{APPLYING THE BMA METHOD: THE STANDARD CHILD REFUSAL CASE ${ }^{10}$ \\ Legal parameters}

The BMA's analysis would follow similar lines to those previously discussed. Again we would look to case law precedents and statute such as the Children Act 1989, which makes the child's needs the paramount consideration. In human rights terms, the child's right to life is seen as trumping the rights of parents to the privacy of family life in their decisions. Nevertheless in practical terms, mediation rather than court 
action may be a first option since it is clear in law and ethics that doctors are generally empowered to act in the child's best interests. Unless there were other materially relevant factors, therefore, the court would only confirm the doctor's existing authority to intervene if necessary and Witnesses are generally well informed about this. The legal and ethical limitation on parental authority which also obliges parents to act in accordance with the child's "best interests" means that life prolonging treatment for a child cannot easily be refused. Recognition of the rights of the family, however, would require that the parents be actively included in discussion and decision making where it is possible to do so without prejudice to the child's welfare.

Since the case example specifically mentions the option of recourse to the courts, the BMA approach would seek to identify, among other issues, how that approach should be made if it is necessary to involve the law. In the 1993 court decision on " $\mathrm{R}$ ", for example, ${ }^{16}$ lengthy consideration was given to whether section 8 of the Children Act or an emergency protection order (which effectively excluded the parents) was the correct way forward. Inclusion of parents as much as possible was seen as significantly preferable. In this legal precedent, parents who were Jehovah's Witnesses felt unable to compromise their beliefs to agree to the treatment with blood products of a young child suffering from leukaemia. They were extremely anxious that the child should receive the best possible care and their objection to blood was not only based on scriptural prohibition but also on the scientific hazards of blood transfusions. They pointed out that rapid advances in medical science meant that alternative blood management procedures were increasingly possible. It was also the parents' wish that even if their daughter were to be given blood where essential, in all the other procedures where it would be possible to use alternatives, this should be done. The judge endorsed this, making clear that even if the court did authorise the use of blood for some treatments, this did not mean that the parents' role as decision makers was over. It "is not a blanket authority to the doctors to do whatever they wish without consultation with them". The conclusions that can be drawn from the case include the fact that doctors must try to accommodate the wishes of parents where it is feasible to do so without damaging the child. They cannot dismiss out of hand the obligation to investigate non-blood alternatives when time permits. Indeed, the judge specifically stated that:

In any situation which is less than imminently life threatening, those medically responsible for the child shall consult with her parents and will consider at every opportunity all alternative forms of management suggested by her parents. In the event that those medically responsible for the child concluding, after such consultation, that there is no reasonable alternative to the administration of blood products, they shall be at liberty to administer such blood products without the consent of the parents. ${ }^{16}$

Although not applicable in this case, in other similar cases where the inquiry concerns consent for the treatment of a child or young person, a crucial assessment is whether or how much the child should be involved in the decision. From a solely legal perspective, it might also be necessary to make inquiries about whether the father has parental responsibility in law and so is legally able to give consent or refusal. If one person with such legal power agrees to the proposed treatment, resort to the courts could be avoided.

\section{Professional guidance}

In the case of children, standard BMA advice since 1981 has included guidance on recourse to the courts if essential and if time allows. In an emergency, the BMA has traditionally pointed out that it is legally and ethically permissible to proceed with blood products despite parental opposition if colleagues agree that it is clinically essential to do so. Current BMA advice emphasises dialogue with families wherever possible. Patient advocates and spiritual advisers can play a useful role in helping ensure that all viewpoints are properly heard. Special support and counselling mechanisms for parents of sick children might also be recommended. In cases such as this, societal expectations about the care and treatment of children would come into play, especially if there were any ambiguity about the likely success of the treatment and concerns about the invasiveness of the procedures.

\section{THE FOUR PRINCIPLES APPROACH}

In both cases, as probably in many others, the four principles solution generally concurs with the BMA's conclusion. In the first case, the principlist would prioritise the adult patient's autonomy and in the second the obligation to benefit and avoid harming the nonautonomous patient. In both cases, the difference between the BMA methodology and the four principles appears to be in the degree of practical detail that can be provided.

This is not unexpected since, arguably, various different approaches draw on a set of common values but categorise them under different headings. Differences between the BMA's methodology and the four principles approach, or indeed other practically viable approaches, may be largely semantic.

For example, a principlist approach classifies various duties under the heading of the autonomy principle. Respect for patient autonomy not only requires doctors to respect patients' wishes but also to communicate well, ascertain patients' true intention, and keep information confidential. All of these things are practical necessities for effective medical practice. If we focus on the importance accorded to confidentiality, we see that a rights based system would value it as a facet of self determination. A duty based or virtue approach would see confidentiality as an aspect of implicit promise keeping on the doctor's part. A pragmatist and utilitarian would focus on the practical utility of confidentiality since patients do not reveal information unless they can trust it will be kept private. A traditionalist would see confidentiality as a cornerstone of professional values going back to the Hippocratic tradition which long preceded any notion of patient autonomy or rights. It could also be described as an intuitive medical response. Within the BMA's methodology, consideration of the scope of confidentiality recurs under the headings of common law duty, statutory obligation-for example, under legislation such as the Data Protection Act and Human Rights Act-a GMC requirement, and as a facet of contemporary public expectation. The same concept features in all these approaches for different reasons but, in practice, the outcome as to when confidentiality should be respected in a particular context is likely to be the same. A principlist-for example, might decide to breach confidentiality under the rubric of avoiding harm (non-maleficence) or promoting justice. A BMA argument in favour of the same decision might be based again on case law, statutory obligation, or compliance with societal expectations that doctors must have regard to the public interest.

A principlist definition of beneficence would be likely to include the need for effective medical training and for doctors to act only within their competence; the obligation to listen to patients, and the requirement to assess risk and harm according to factual clinical indicators as well as patients' views. The point that I am making here is an obvious one: we may pigeonhole a series of core values in various different ways but ultimately most systems result in similar solutions although the reasoning along the way may be expressed in terms of 
duties, rights, law, or best practice. In some cases, it may be important to analyse carefully the precise reasons why one principle or value should trump another when they clash but in most common dilemmas this may be a case of a difference without a real distinction.

\section{WHY HAVE DIFFERENT METHODOLOGIES?}

Self evidently, genetic knowledge highlights the interconnection of individuals who share the same DNA and can challenge notions of the primacy of personal choice and individual privacy. In this sphere, individuals' decisions are particularly likely to impinge on others and that fact differentiates them somewhat from other spheres of medicine where personal choice is the main determinant. For dilemmas in this area concerning confidentiality or notions of intergenerational justice, a moral approach reflecting communitarian values and mutual moral responsibilities rather than autonomy might be a particularly helpful form of analysis. ${ }^{17}$ Conceivably, other specialised approaches and methodologies might be suited to particular spheres of medical, psychiatric, psychological, or nursing care. While "browsing in the rich and varied pastures of health care ethics", ${ }^{18}$ as Professor Gillon so eloquently puts it, we find that attention is drawn to a range of contrasting approaches including feminist, narrative, and virtue ethics. Medical students' textbooks also proffer information about theories based on consequentialism, casuistry, contextualism, intuitionism, pragmatism, relativism, and liberalism as well as rights and duties based methodologies. ${ }^{19}$ To the philosophically uninitiated, this is a daunting prospect. In contrast to this plethora of potentially useful methodologies, it is claimed that the "four principles plus scope" approach, if sympathetically interpreted, can encompass all moral issues, not only those arising in health care ${ }^{18}$ No wonder, therefore, that so many practising health professionals clutch with relief at the four principles, which provide a familiar moral language and seem to encompass everything.

Part of the attraction must be the implication that a mere four factors need to be considered but for this to be the case, a certain elasticity of definition is required. In fact, on analysis it seems that the four principles eventually come to include all the values, guidelines, codes, and legislation that one can imagine. Thus, since the four principles have come to be interpreted as a portfolio term meaning "all the important stuff in life and decision making", there is considerable overlap between them and the BMA's eclectic methodology. Certainly, the BMA approach shares much of the language and philosophy. It is impossible to avoid doing so, since the principlist approach partly draws on the same traditional concepts that have always been considered central to medicine. Arguably, however, there is still considerable value in having a range of methodologies available and conceivably some approaches will prove particularly helpful in clarifying particular strands of thought in particular contexts.

\section{CONCLUSION}

Medical ethics is the application of ethical reasoning to medical decision making. It is a rich and varied discipline often combining an appeal to different perspectives and principles as well as taking account of information and guidance of various sorts. It is concerned with critical reflection about "norms or values, good or bad, right or wrong, and what ought or ought not to be done in the context of medical practice" ${ }^{20}$ It deals with ordinary everyday practice as well as with the unusual, dramatic, and contentious and involves a search for reasoned answers in situations where different moral concerns, interests or priorities conflict. This requires critical scrutiny of the issues and careful consideration of various options.

The BMA takes a reasoned eclectic approach to ethical analysis. It has developed its own methodology for helping doctors to analyse and resolve ethical questions and for dissecting dilemmas. Underpinned by rational analysis and awareness of different philosophical approaches, the answers must above all be intensely practical and credible. Sometimes the law gives a clear direction, emphasising, for example, that a competent adult has the right to refuse life prolonging treatment even if the refusal results in death. Even superficially simple queries, such as how much information to give a patient, or whether children can choose treatment for themselves, cannot be answered fully without mentioning how legal cases and ethical discussions influence medical practice and vice versa. In its efforts to provide a very practical and "hands on" approach to medical ethics the BMA tends to use key values that are familiar to practising doctors. They include respect for patients' rights to self determination and confidentiality, the duty for doctors to act with honesty and integrity to promote patients' best interests while having regard to societal standards, non-discrimination, and equity. Although we resort to a lengthier list of things to consider, the solutions that emerge are often likely to coincide with the four principles approach.

\section{REFERENCES}

1 The Bristol Royal Infirmary Inquiry. The inquiry into the management of care of children receiving complex heart surgery at the Bristol Royal Infirmary. Interim report: removal and retention of human material. London: Central Office of Information, 2000

2 The Royal Liverpool Children's Inquiry. The Royal Liverpool Children's Inquiry report. London: The Stationery Office, 2001 (HC12-II)

3 Jonsen AR. Clinical ethics and the four principles. In: Gillon R, Lloyd A, eds. Principles of health care ethics. Chichester: John Wiley and Sons, 1994.

4 Lord Chief Justice Press release 17 January 2001.

5 Morgan DM. Issues in medical law and ethics. London: Cavendish Publishing, 2001:5.

6 BMA. The impact of the Human Rights Act 1998 on medical decision making. London: BMA, 2000.

7 Mason J, McCall Smith RA, Laurie GT. Law and medical ethics [6th ed]. Edinburgh: Butterworths, 2002:5

8 BMA. The medical profession and human rights: handbook for a changing world. London: Zed Books, 2001:ch 7.

9 Boyd KM, Higgs R, Pinching AJ. The new dictionary of medical ethics. London: BM Publishing Group, 1997: 113

10 Gillon R. Four scenarios. J Med Ethics 2003;29:267-8.

11 Re T (adult: refusal of medical treatment) [1992] 4 All ER, 650.

12 General Medical Council. Seeking patients' consent: the ethical considerations. London: GMC, 1998.

13 UK Blood Transfusion Services. Guidelines for the blood transfusion services in the UK [6th edn]. London: The Stationery Office, 2002. 14 BMA. The handbook of medical ethics. London: BMA, 1981:33-4.

15 Watch Tower Bible and Tract Society of Pennsylvania. Family care and medical management for Jehovah's Witnesses. New York: Watch Tower Bible and Tract Society of New York, 1995.

$16 \operatorname{Re} R$ (minor) [1993], Butterworths Medico-Legal Reports, 15 BKLR, 73

17 BMA. Human genetics: choice and responsibility. Oxford: Oxford University Press, 1998

18 Gillon R. Preface. In: Gillon R, Lloyd A, eds. Principles of health care ethics. Chichester: John Wiley and Sons, 1994.

19 Schwartz L, Preece PE, Hendry RA. Medical ethics: a case-based approach. Edinburgh: Elsevier, 2002:ch 1.

20 Gillon R. Philosophical medical ethics. Chichester: John Wiley and sons, 1985:2. 